\title{
To Compare the Effect Between Two Different Priorities Dual Task Balance Training in Older Adults with Balance Impairment
}

\author{
Meenakshi Verma, Supriya Awasthi, Bhavna Sharma
}

Assistant Professor, Department of Physiotherapy, Sharda University, India

\section{Article Info}

Volume 7, Issue 4

Page Number: 238-250

Publication Issue :

July-August-2020

\section{Article History}

Accepted : 13 Aug 2020

Published : 19 Aug 2020

\section{ABSTRACT}

Background and Purpose: Balance is controlled through a complex process involving sensory, visual, vestibular and cerebral functioning which get affected by various neurological disorders such as fall. The purpose of the study was to compare the efficiency of three different balance training strategies in an effort to understand the mechanisms underlying training-related changes in dual task balance performance of older adults with balance impairment.

Methods: 45 older adults with balance impairment were recruited and randomly assigned to three groups. Group one received single task balance training, group two received dual task training balance training under fixed priority, group three received dual task balance training under variable priority. Subjects received one-hour individualized training sessions, five times in a week for two weeks. Berg balance scale and time up and go test were the outcome measure and their scores for all groups were taken prior and after the training.

Results: One-way analysis of variance was used to analyse the difference among the balance improvement in Group one, two and three. And the results revealed that post intervention scores were highly significant $(p \leq 0.05)$ in group two and group three performed better than group one.

Conclusion: In conclusion, dual task training is effective in improving balance under dual task context in older adults with balance impairment, and single task training may not generalize to balance performance under dual task conditions.

Keywords : Balance, Fall, Berg balance scale, Time up and go test, Dual task, Fixed priority, Variable priority

\section{INTRODUCTION} Falling is one of the most serious problems associated and reaches $35 \%$ per year among those 75 and older. ${ }^{2,3}$ with ageing. ${ }^{1}$ Falls are the most frequent cause of The incidence of falls increases with age and is more injury- related morbidity and mortality among the common in women. Sheldon found that $21 \%$ of men 
and $43 \%$ of women were affected ${ }^{4}$ Poor balance is initially detectable in the $6^{\text {th }}$ decade of life but then accelerated so that it becomes the rules rather than the exception by one's late eighties. ${ }^{5}$ A single fall often results in a fear of falling, which leads to a loss of confidence in one's ability to perform routine tasks, restriction in activities, social isolation, increase dependence on others. ${ }^{6}$ Balance disturbance frequently cause elderly people to seek medical advice and admission to hospitals and residential homes. ${ }^{7}$

Falls are costly and have potentially devastating physical, psychological and social consequences. Nonfatal falls often lead to physical injury, reduced levels of activity, loss of confidence, altered lifestyle in elderly people.8,9,10 Identification of significant risk factors is an important step towards fall prevention. Several studies have been performed among both home living and institutionalised populations to define risk factors associated with falls. ${ }^{11-15}$

These risk factors have included both- intrinsic or personal factors (example- Balance impairment, neurological disorders, postural hypotension, and medication use $)^{1,8,10,16-18}$ and extrinsic or environmental factors (example- Ill fitting footwear, poor lighting, slippery surface and inappropriate furniture. ${ }^{1,8-10,18-20}$ Older adults with balance impairment are frequently referred for physical therapy to improve balance control and reduce the risk of falling. Recent studies have shown that such program can reduce the rate of falls in elderly.

There are multifactorial intervention have been introduced which included eliminate environmental hazards, improve home support, provide opportunities for socialization and encouragement, modify medication, provide balance training, involve family and provide follow up. ${ }^{9,21,22}$ In context of balance there are many different types of exercise programs were studied, like tai chai exercise, high resistance weight training, gait training, transfer skill training. So it was difficult to determine which type was most effective. ${ }^{9,21}$

Keeping this in mind, this study is designed with the purpose of identifying the most appropriate balance training program under single and dual task condition in older adults with balance impairment because no research have examined the effects of training balance under single task versus dual task (fixed priority versus variable priority) conditions in older adults.

Single task training involves practicing functional task requiring balance (example Standing, walking, transfer) in isolation. In previous researches, the therapist may vary the condition to increase the challenge to balance during performance under which the subject practices for example - changing the availability of sensory cues (reduce visual cues by asking the participants to close your eyes), or support surface conditions (exampleWalking on a flat surface versus an inclined surface. ${ }^{23-}$ 24

Dual task method, which requires participants to perform multiple tasks simultaneously, has been used to investigate the effect of cognitive tasks on postural control and vice-versa. It has been shown that the ability to maintain postural stability is reduced when performing two or more tasks concurrently \& these deficits are increased in elderly people with balance impairment. ${ }^{25-28}$

Recent research proved that older adults who perform poorly under dual- task conditions are at increased risk for falls.29,30 Some studies also compared the effectiveness of whole/ dual-task training under various set of instructions (fixed priority versus variable priority). In fixed priority condition, participants were asked to place the same amount of attention on both tasks at all times, whereas in variable 
priority condition, attention was switched between tasks.

Kramer et al ${ }^{31}$ compared dual task training under two instructional sets; fixed priority and variable priority instructional sets. In their study included a monitoring task in conjuction with an alphabet-arithmetic task. Results showed that the variable priority group improved (increased accuracy and decreased response time) significantly more than fixed priority group and dual task processing skills learned during variable priority training transferred to novel tasks. In this study, the effect of instructional set on dual task balance training in elders is not known. In light of research indicating that inability to perform concurrent tasks is a contributing factor to instability and falls in many older adults, it has been suggested that training under both single and dual -task condition is necessary to optimise functional independence and reduce falls in elderly people. So my purpose of study is to compare the effects of training balance under single task versus dual task (fixed priority versus variable priority) in older adults with balance impairment.

Three balance scale are used to assess the outcomes of both interventions. They are Time Up and Go Test and Berg Balance Scale. These scales have good reliability and validity which will be discussed in review of literature. These scales have been selected for study because

1. They are very simple to administer

2. They are quick and practical.

3. They are easy to be conducted in Indian clinical setting

4. The contents of these scales closely mimic the day to day activities and are easy for the patients to understand.

\section{METOHDS}

\section{Selection and description of participants:}

A sample of convenience of 45 older adults with balance impairment took part in this study. Subjects were gathered through a Free Physiotherapy Camp organized at Department of Physiotherapy, Sharda Hospital, Greater Noida. Subjects who fulfilled the inclusion criteria and were ready to attend exercise program regularly were selected.

To participate subjects had to meet the inclusion criteria: (i) Subjects with age of 65 of years or above. (ii) Subjects with history of one fall within the previous year. (iii) Independent ambulators with ability to walk 9 meter without any assistance. (iv)Subjects who were independent in their activities of daily living. (v) Subjects who scored greater than 24 on mini mental status examination score.39

Exclusion Criteria for the subjects were: (i) History of any other severe neurological, musculoskeletal and cardiovascular condition that affected balance. (ii) Any history of dizziness, depression. (iii) Any uncorrected severe hearing \& visual impairment which will affect the balance in elderly. (iv) Receipt of physical therapy or enrollment in any other formal exercise program at the same time.

\section{Technical information:}

A pre-post experimental design was used. The subjects were randomly distributed using online websiteRandomization.com (https://:www.randomization.com) into 3 groups. A detailed explanation of the procedure was given to the patients after which they signed informed consent. Then the subjects were assessed on 3 balance scales included in our study: Berg balance scale, time up and go test. Balance training sessions followed Gentile's 
taxonomy of movement tasks, a theoretical framework for retraining motor control.

This training progresses subjects from: body stability, to body stability plus manipulation, then body transport and finally transport plus manipulation.

Group 1 received Single task condition training which included balance activities such as standing with reduced base of support, tandem standing, standing with eyes closed.

Group 2 received Dual task condition training under fixed priority which included same set of balance tasks as group 1 while simultaneously performing auditory and visual discrimination tasks as well as cognitive tasks such as substraction and subjects were directed to maintain attention on both postural and secondary tasks at all times.

Group 3 received Dual task condition training under variable priority which included half training was done with a focus on postural task performance, and half had a focus on secondary task performance such as semi tandem with eyes closed and arm alteration was postural task and spell word backward is secondary task and attention was switched between the task.

Subjects were then assessed on two balance scalesBerg Balance Scale and Time Up and Go Test.

\section{Statistics}

The data was managed on excel spread sheet and was analysed using SPSS (Statistical Package for social sciences for windows) software, version 12. A One way analysis of variance was used to analyse the difference among the balance improvement in Group 1, 2, 3. Post hoc analysis of significant $\mathrm{F}$ ratio $(\mathrm{p} \leq 0.05)$ was conducted using Duncan mean test. Student t- test (paired) used to analyse the difference between the balance improvement within the group. A significance level of $\mathrm{p} \leq 0.05$ was fixed.

\section{RESULTS}

The group 1 receiving single task condition balance training program consisting of 12 males and 3 females with a mean age of 68.47 years. Group 2 receiving dual task condition with fixed priority balance training program consisting of 12 males and 3 females with a mean age of 68.20 years. Group 3 receiving dual task condition balance training with variable priority balance training program consisting of 12 males and 3 females with a mean age of 68.07 years. All three groups were matched in terms of age, height, weight (table 1.1. and figure 1.1). One-way analysis of variance was used to compare the performance of subjects of group 1, 2, 3 on Berg balance scale, and Time up and go test.

1) Pre-intervention scores of Berg balance scale (table

\section{2 and figure 1.2 )}

All the groups did not showed significant difference $(\mathrm{F}=0.8543, \mathrm{p} \leq 0.05)$ indicating

that all three groups were matched in terms of Berg balance scale. Group 1 (mean $=49.55, \mathrm{SD}=1.88$ ), Group $2($ mean $=50.33, \mathrm{SD}=1.75)$, Group 3 (mean $=50.20, \mathrm{SD}=$ 1.74).

Pre-intervention scores of Time up and go test for balance (table 1.2 and figure 1.3 )

All the groups did not showed significant difference $(\mathrm{F}=0.5513, \mathrm{p} \leq 0.05)$ indicating that all three groups were matched in terms of Time Up and Go Test. Group1 (mean=11.14, SD=1.24), Group2 (mean=11.33, $\mathrm{SD}=1.03)$, Group3 (mean=11.57, $\mathrm{SD}=1.06)$. 


\section{Post- intervention scores of Berg balance scale (table}

\section{3 and figure 1.2)}

Results revealed significant difference in group 1 versus group 2 and group 1 versus

group 3 with $F$ value $=9.1953, p \leq 0.05$. Group 1

(mean=54.33, SD=1.63), Group 2 (mean= 55.66, SD=

$0.48)$, Group 3 (mean $=55.80, \mathrm{SD}=0.56$ )

Post- intervention scores of Timed up and go test (table 1.3 and figure1.3)

Results revealed significant difference in group 1 versus group 2 and group 1 versus group 3 with $\mathrm{F}=$ $6.68451, \mathrm{p} \leq 0.05$. Group 1 (mean $=9.70, \mathrm{SD}=0.80$ ), Group 2 (mean $=8.80, \mathrm{SD}=0.84)$, Group $3($ mean $=8.72$, $\mathrm{SD}=0.75)$

\section{DISCUSSION}

The present study was undertaken to evaluate the effectiveness of single task versus dual task condition balance training in older adults with balance impairment.

The results of study have revealed that subjects in group 1 (single task condition balance training), group 2 (dual task condition balance training with fixed priority), group 3 (dual task condition balance training with variable priority) benefited from balance training intervention with a significant improvement in postintervention balance scores on Berg balance scale and Time up and go test.

Secondarily, post intervention scores were highly significant in among the groups but group 2 and group 3 performed better than group 1 . So dual task condition balance training program was found to be more effective in improving balance in older adults with balance impairment.
One factor that might have contributed to improved scores in group 2 and group 3 could be based on task coordination and management theory proposed by Kramer et al. According to this theory practicing two tasks together (not a single task practice) allows participants to develop task coordination skills. Thus, a possible explanation of this outcome is that the efficient integration and coordination between the two tasks acquired during dual task training is crucial for improving dual task performance. Alternatively, according to Task Automatization hypothesis, practicing only one task at a time (single task training) allows participants to automatize the performance of individual tasks. As a result, the processing demand required to perform the tasks is decreased, leading to more rapid development of skills. ${ }^{39-42}$

Another factor that might have contribute to improved scores in group 2 and group 3 was that they had instructional set in dual task training. Research by Kramer et al suggests that who receive dual task training with variable priority instructions have advantage over those who receive training with fixed priority instructions. These researchers found that participants in dual task training groups with either fixed priority or variable priority instructions could learn to coordinate the two tasks. However, after training, the processing demand required to perform the tasks was less when their attention was shifted between the two tasks, as was required in dual task training with variable priority instructions group. This could explain why the participants in our dual task training with variable instructions group were able to learn faster. Although in our results we could not found a significant difference between fixed priority and variable priority instruction but the subjects who received variable priority have done less number of miss steps and less errors in verbal response during the 
intervention period as compare to fixed priority instructional sets. ${ }^{32-34}$

After two weeks intervention program, subjects in all training groups significantly improved performance on Berg balance score and Time up and go. The Berg balance scores increased about 5 to 6 point in all groups. According to Shumway Cook et al, "In the range of 56 to 54 , each 1point drop in berg balance scale scores is associated with a $3 \%$ to $4 \%$ increase in fall risk. In the range of 54 to 46 , a 1 point change in berg balance scale scored led to $6 \%$ to $8 \%$ is increase in fall risk using this model, balance training in our was associated with berg balance scores, suggesting a $40 \%$ reduction in fall risk. ${ }^{35}$

Similar results with Time up and go test which shows more improvement under dual task condition. According to Richardson et al, ${ }^{36}$ " the predictive results of time up and go, if subjects completed the test less than 10 seconds, they are freely mobile. If the subjects completed it less than 20 seconds, they are mostly independent, if the subjects completed it in 20 to 29 seconds, they are variable mobility. If the subjects completed it more than 30 seconds, they have impaired mobility. In our results, subjects completed the test less than or equal to 10 seconds. Thus, the outcomes suggest that dual task condition balance training is more effective than single task and the importance of instructional set during balance training.

\section{CLINICAL IMPLICATION}

This study found that it was feasible to implement individual dual task training, combining traditional intervention with a variety of cognitive tasks, in community-dwelling older adults with balance impairment. We also found that older adults could in fact adhere to instructional sets regarding attentional forces. They successfully allocated their attention to task in which they were instructed. Thus, results may generalize to similar older adults with balance impairment, excepting those with a significant neurological or musculoskeletal diagnosis.

\section{FUTURE RESEARCH}

Future research is needed longer time period of intervention should be done with follow up period to identify whether the effect of training may be sustained or not and what additional strategies (such as the inclusion of home exercise program following discharge) are necessary to sustain and maximize benefits. The relevance of this study can be increased by taking a larger sample of subjects from different sectors of society. The study involved only community dwelling older adults who were living an active life style and not institutionalized or hospitalized. Future research should bed one to see the effect of this intervention in institutionalized or hospitalized older adults.

\section{LIMITATION OF STUDY}

1. The study has limited sample size and short period of intervention. Increasing the sample size would have increased the statistical power of the study.

2. The result of the present study cannot be generalize to all the neurological conditions and musculoskeletal conditions because of the difference in the cognitive and musculoskeletal levels in different conditions.

3. Study was not double blinded.

4. The result of the study cannot be generalize for the subjects with cognitive decline.

\section{VII.CONCLUSION}

The result of the present study clearly states that dual task training is effective in improving balance under dual task context in older adults with balance impairment, and single task training may not generalize to balance performance under dual task 
conditions. The instructional set was an important in dual task performance. The variable priority instructional set offered advantages over the fixed priority instructional set in terms of the rate of learning and ability to maintain the skill level achieved during training. Although in our results we could not found a significant difference between fixed priority and variable priority instruction but the subjects who received variable priority have done less number of miss steps and less errors in verbal response during the intervention period as compare to fixed priority instructional sets.

Thus, the alternate hypothesis stated in the beginning of the study, that is, Dual task condition balance training under two priorities instructional sets acts as better technique from single task balance training in older adults with balance impairment, have been proved.

\section{DISCLOSURE}

The author report no conflicts of interest in this work.

\section{REFERENCES}

[1]. Brian E. Maki, Pamela J. Holiday, Anne K. Topper (1991). Fear of falling and Postural control performance in the elderly. Journal of Gerontology, 46 (4), M 123 -67131.

[2]. Michael C. Nevitt, Steven R. Cummings, Estie S. Hudes (1991). Risk factors For injurious falls: A prospective study. Journal of Gerontology, 46 (5), M 164-170.

[3]. Mary E. Tinrtti and Mark Speechley (1989). Prevention of falls among the Elderly. The New England Journal Of Medicine, 320 (16), 1055- 1059.

[4]. Richard C. Nelson and Murlidhar A. Amin (1990). Emergency care of the Eldery. Falls in elderly, 8 (2), 309-324.
[5]. Wolfson L., Whipple R, Derby C.A., Amerman, P., Murphy, T., Tobin,

[6]. J.N., and Nashner, L. (1992). A dynamic posturography study of balance in healthy eldery. Neurology, 42, 2069-2075.

[7]. Vellas B.J., Wayne S.J., Romero, L.J., Baumgatner R.N. and Garry, P.J (1997). Fear of falling restriction of miobility in elderly fallers. Age and Ageing, 26, 189-193.

[8]. Mathias S., Nayak and Isaacs, B. (1986). Balance in eldery patients: The "Get- up and Go" Test. Archives of physical medicine and rehabilitation, 67, 387-389.

[9]. Campbell AJ, Borrie MJ, Spears GF, et al. (1990) Circumstances and consequences of falls experienced by a community populations 70 years and over during a prospectives study. Age and ageing, 19, 136-141.

[10]. Tinetti ME., Baker D.I., McAvay G., et al.(1994) A multifactorial intervention to reduce the risk of falling among elderly people living in the community. New England Journal Medicine, 331, 821-827.

[11]. Sattin RW. (1992) Falls among older persons: a persons: a public health perspective. Annual Review Public Health, 13, 489-508.

[12]. Tinetti M.E., Williams T.F., and Mayewski R. (1986). Fall risk index for elderly patients based on number of chronic disabilities. The American Journal Of Medicine, 80, 429- 435

[13]. Granek E., Baker S.P., Abbey H., Robinson E., Myers A.H. Samkoff, J.S. and Klein, L.E. (1987). Medications and diagnosis in relation to falls in long term care facility. Journal Of America Geriatric Society, 35, 503-511.

[14]. Whipple R.H., Wolfson L.I. and Amerman P.M.(1987). The relationship of knee and ankle weakness to falls in nursing home residents: An isokinetic study. Journal Of American Geriatric Society, 35, 13-20. 
[15]. Buchner, D.M. and Larson E.B.(1987). Falls and fractures in patients with Alzheimer-Type Dementia. Journal Of American Medical Association, 257, 1492-1495.

[16]. Tobis J.S., Reinsch S., Swanson J.M., Byrd M and Scharf T. (1985). Visual perception dominance of fallers among communitydwelling older adults. Journal Of American Geriatric Society, 33, 330-333.

[17]. Nelson R.C., Amin M.A. (1990). Falls in the elderly. Emergency Med Clinical North America, 8, 309-399.

[18]. Tinetti M.E., Speechley M., Ginter S.F.(1988). Risk factors for falls among elderly persons living in the community. New England Journal Of medicine, 319, 1701-1707.

[19]. Overstall PW, Exton-Smith A.N., Imms F.J., Johnson A.L. (1977). Falls In the elderly realated to postural imbalance. British Medical Journal, 1, 261-264.

[20]. Nickens H.(1985). Intrinsic factors in falling among the elderly. Archives Internal Medicine, $145,1089-1093$.

[21]. Tinetti M.E., Speechley M. (1989). Prevention of falls among the elderly. New England Journal Of Medicine, 320, 1055-1059.

[22]. Dawn A., Skelton and Susie M. Dinan (1999). Exercise for falls management: Rationale for an exercise programme aimed at reducing postural instability. Physiotherapy Theory and Practice, 15, 105-120.

[23]. James O Judge, Carleen Lindsey, Michael Underwood (1993). Balance Improvement in older women: effects of exercise training, 73, 254-265.

[24]. Alexander NB, Galecki AT, Grenier ML et al (2001). Task-specific resistance training to improve the ability of activities of daily livingimpaired older adults to rise from a bed and from a chair. Journal of American Geriatric Society. 49, 1418-1427.
[25]. Lord SR, Castell S. Physical activity program for older persons: effect on balance, strength, neuromuscular control, and reaction time. Archives of Physical Medicine Rehabilitation, 75, 648-652.

[26]. Brown L.A., Shumway-Cook A. (1999). Attentional demands and postural recovery: the effects of aging. Journal of Gerontology, 54, M165-171.

[27]. Kerr B., Condon S.M., McDonald L.A.(1985). Cognitive spatial processing and the regulation of posture Journal Experimental Psychology Human Perceptual Performance, 11, 617-622.

[28]. Brauser S.G., Woollacott M, Shumway-Cook A. (2002). The interacting effects of cognitive demand and recovery of postural stability in balance-impaired elderly persons. Journal of Gerontology, 56, M489-496.

[29]. Shumway-Cook A., Woollacott M., Kerns K.A. (1997). The effects of two types of cognitive tasks on postural stability in older adults with and without a history of falls. Journal of Gerontology, 52, M 232-240.

[30]. Connell B.R., Wolf S.L., Atlanta FICSIT Group. (1997). Environmental and behavioural circumstances associated with falls at home among healthy elderly individuals. Archives of Physical Medicine and Rehabilitation, 78, 179186.

[31]. Verghese J., Buschke H., Viola L., et al (2002). Validity of divided attention tasks in predicting falls in older individuals: a preliminary study. Journal of American Geriatric Society, 50, 1572-1576.

[32]. Kramer A.F., Larish J.F., Strayer D.L. (1995). Training for attentional control in dual task settings: a comparison of young and old adults. Journal of Experimental Application, 1, 50-76.

[33]. Patima Silsupadol, Vipul Lugade, ShumwayCook et al (2009). Training related changes in dual task walking performance of elderly 
persons with balance impairment: A double blind randomised controlled trial. Gait and Posture.

[34]. Patima Silsupadol, Ka-Chun Siu, ShumwayCook. (2006). Training of balance under single and dual task condition in older adults with balance impairment. Physical therapy, 86, 269-281

[35]. Patima Silsupadol, Vipul Lugade, ShumwayCook et al (2009). Effects of single task versus dual task training on balance performance in adults: A double blind, randomised controlled trail.

[36]. Steffen T.M., Hacker, T.A. and Mollinger L. (2002). Age and gender related test performance in community-dwelling elderly people: Six minute walk test, berg balance scale, time up and go test, and gait speeds. Physical therapy, 82, 128-137.

[37]. Choi JH, Kim BR, Han EY, Kim SM. The effect of dual-task training on balance and cognition in patients with subacute post-stroke. Ann Rehabil Med. 2015;39(1):81-90. doi:10.5535/arm.2015.39.1.81

[38]. Shumway-Cook A., Woollacott H. Assessment and treatment of the patient with mobility disorders. Chapter 14, Motor control, 322-324.

\section{Cite this article as :}

Meenakshi Verma, Supriya Awasthi, Bhavna Sharma, "To Compare the Effect Between Two Different Priorities Dual Task Balance Training in Older Adults with Balance Impairment", International Journal of Scientific Research in Science and Technology (IJSRST), Online ISSN : 2395-602X, Print ISSN : 23956011, Volume 7 Issue 4, pp. 238-250, July-August 2020. Available at

doi $\quad$ : https://doi.org/10.32628/IJSRST207472

Journal URL : http://ijsrst.com/IJSRST207472 
Table 1.1. Demographic Data : Comparison among Group 1, Group 2, Group3 (One way ANOVA)

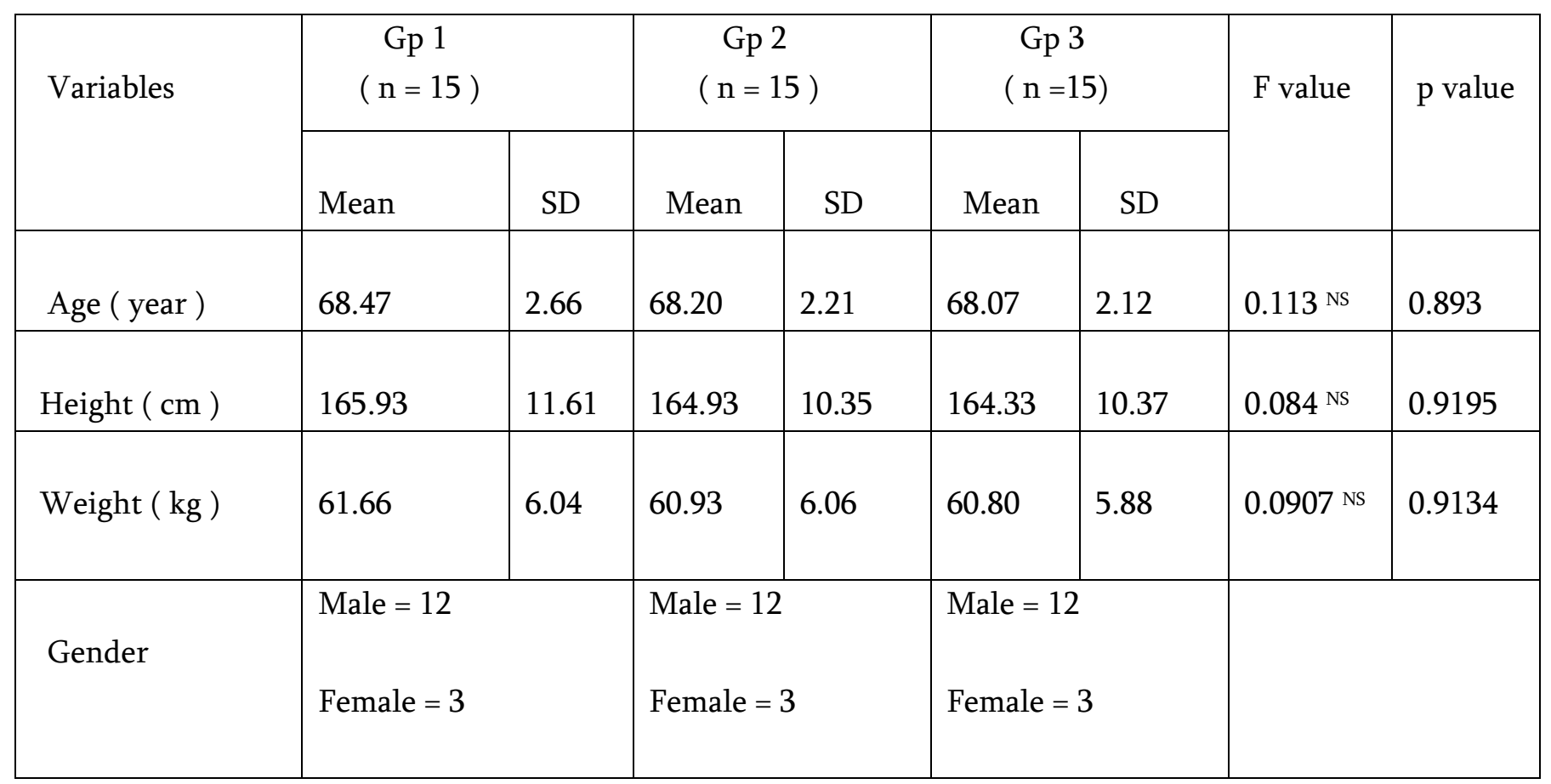

NS $\quad=\quad$ Not significant at $\mathrm{p} \leq 0.05$ level

$\mathrm{n} \quad=$ number of subjects

$\mathrm{Gp} \quad=$ Group

Group $1=\quad$ Single task condition balance training

Group $2=\quad$ Dual task condition with fixed priority balance training

Group 3 = Dual task condition with variable priority balance training 
Table 1.2. Comparison of Pre- intervention scores of Berg balance scale, Timed Up and Go Test among Group 1, 2, 3 ( One way ANOVA)

\begin{tabular}{|c|c|c|c|c|c|c|c|c|c|c|c|}
\hline \multirow{3}{*}{ Variable } & \multirow{2}{*}{\multicolumn{2}{|c|}{$\begin{array}{c}\mathrm{G} 1 \\
(\mathrm{n}=15)\end{array}$}} & \multirow{2}{*}{\multicolumn{2}{|c|}{$\begin{array}{c}\mathrm{G} 2 \\
(\mathrm{n}=15)\end{array}$}} & \multirow{2}{*}{\multicolumn{2}{|c|}{$\begin{array}{c}\text { G3 } \\
(\mathrm{n}=15)\end{array}$}} & \multirow{3}{*}{$F$ value } & \multirow{3}{*}{$\mathrm{p}$ value } & \multicolumn{3}{|c|}{ Mean difference } \\
\hline & & & & & & & & & C1 & G1 vs & G2 vs \\
\hline & Mean & SD & Mean & SD & Mean & SD & & & G2 & & \\
\hline $\begin{array}{l}\text { Berg balance } \\
\text { scale }\end{array}$ & 49.55 & 1.88 & 50.33 & 1.75 & 50.20 & 1.74 & $0.8543 \mathrm{NS}$ & 0.4328 & 0.78 & 0.65 & 0.13 \\
\hline $\begin{array}{c}\text { Time Up and } \\
\text { Go Test }\end{array}$ & 11.14 & 1.24 & 11.33 & 1.03 & 11.57 & 1.06 & $0.5513^{\mathrm{NS}}$ & 0.5803 & 0.19 & 0.43 & 0.24 \\
\hline
\end{tabular}

NS $=$ Not significant

$\mathrm{G}=$ Group

$\mathrm{n} \quad=\quad$ Number of subjects

Table 1.3. Comparison of Post- intervention scores of Berg balance scale, Timed Up and Go test among Group1, 2, 3 (One way ANOVA and Duncan's mean test)

\begin{tabular}{|c|c|c|c|c|c|c|c|c|c|c|c|}
\hline \multirow[t]{2}{*}{ Variable } & \multicolumn{2}{|c|}{$\begin{array}{c}\text { G1 } \\
(\mathrm{n}=15)\end{array}$} & \multicolumn{2}{|c|}{$\begin{array}{c}\text { G } 2 \\
(\mathrm{n}=15)\end{array}$} & \multicolumn{2}{|c|}{$\begin{array}{c}\text { G3 } \\
(\mathrm{n}=15)\end{array}$} & \multirow[t]{2}{*}{ F value } & \multirow[t]{2}{*}{$\begin{array}{c}\mathrm{p} \\
\text { value }\end{array}$} & \multicolumn{3}{|c|}{ Mean difference } \\
\hline & Mean & $\mathrm{SD}$ & Mean & SD & Mean & SD & & & $\begin{array}{l}\text { G1 vs } \\
\text { G2 }\end{array}$ & $\begin{array}{l}\text { G1 vs } \\
\text { G3 }\end{array}$ & $\begin{array}{l}\text { G2 vs } \\
\text { G3 }\end{array}$ \\
\hline $\begin{array}{l}\text { Berg } \\
\text { balance } \\
\text { scale }\end{array}$ & 54.33 & 1.63 & 55.65 & 0.48 & 55.80 & 0.56 & 9.1953* & 0.0005 & $1.32^{*}$ & $1.47^{*}$ & $0.15^{\mathrm{NS}}$ \\
\hline $\begin{array}{l}\text { Time Up } \\
\text { and Go } \\
\text { Test }\end{array}$ & 9.70 & 0.80 & 8.08 & 0.84 & 8.72 & 0.75 & $6.8451^{*}$ & 0.0027 & $1.62^{*}$ & $0.98^{*}$ & $0.64^{\mathrm{NS}}$ \\
\hline \multicolumn{12}{|c|}{ Significant $\leq 0.05$ level } \\
\hline $\begin{array}{l}\mathrm{NS}= \\
\mathrm{G}= \\
\mathrm{n}=\end{array}$ & $\begin{array}{l}\text { Not } \\
\text { Grou } \\
\text { num }\end{array}$ & ficant & & & & & & & & & \\
\hline
\end{tabular}


Figure 1.1. Comparison of age among the group 1, 2, 3

Comparison of age among the group 1, group 2 and group 3

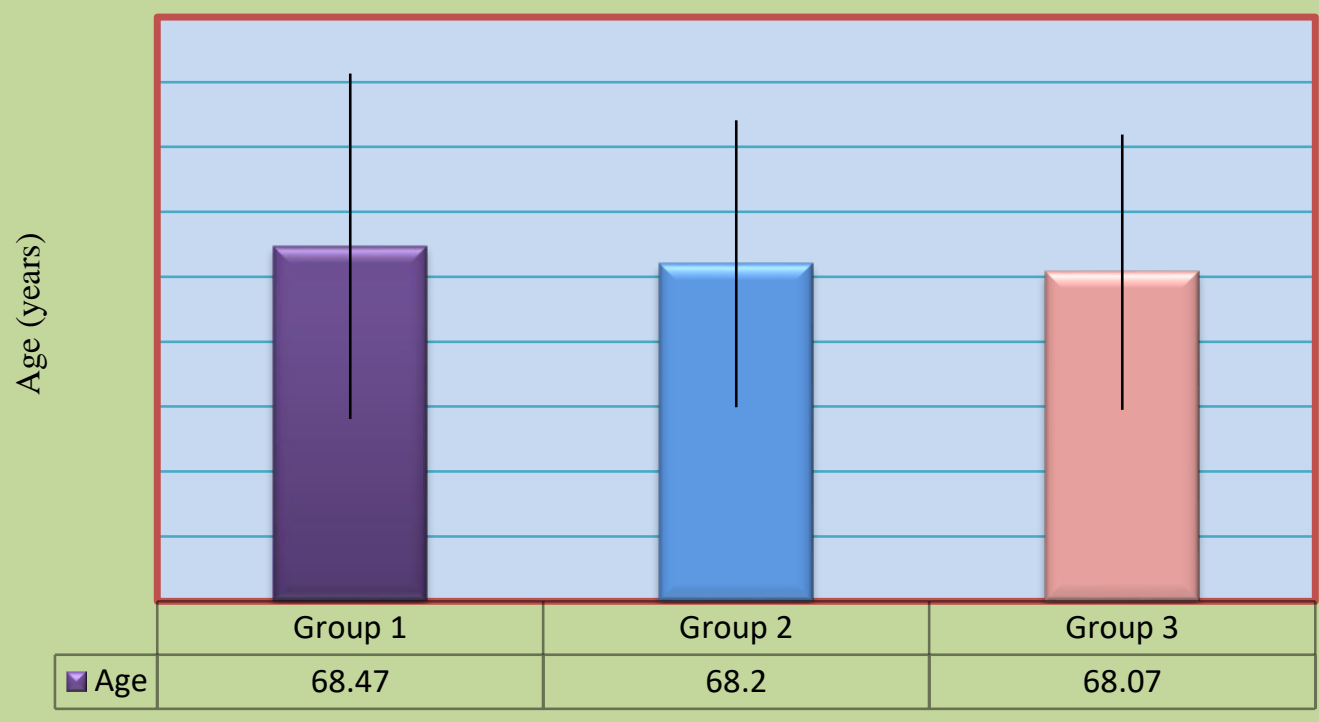

Group $1=$ Single task condition balance training

Group 2 = Dual task condition balance training with Fixed Priority

Group 3 = Dual task condition balance training with Variable Priority

Figure 1.2. Comparison of pre and post intervention of berg balance scale scores among group 1, 2, 3

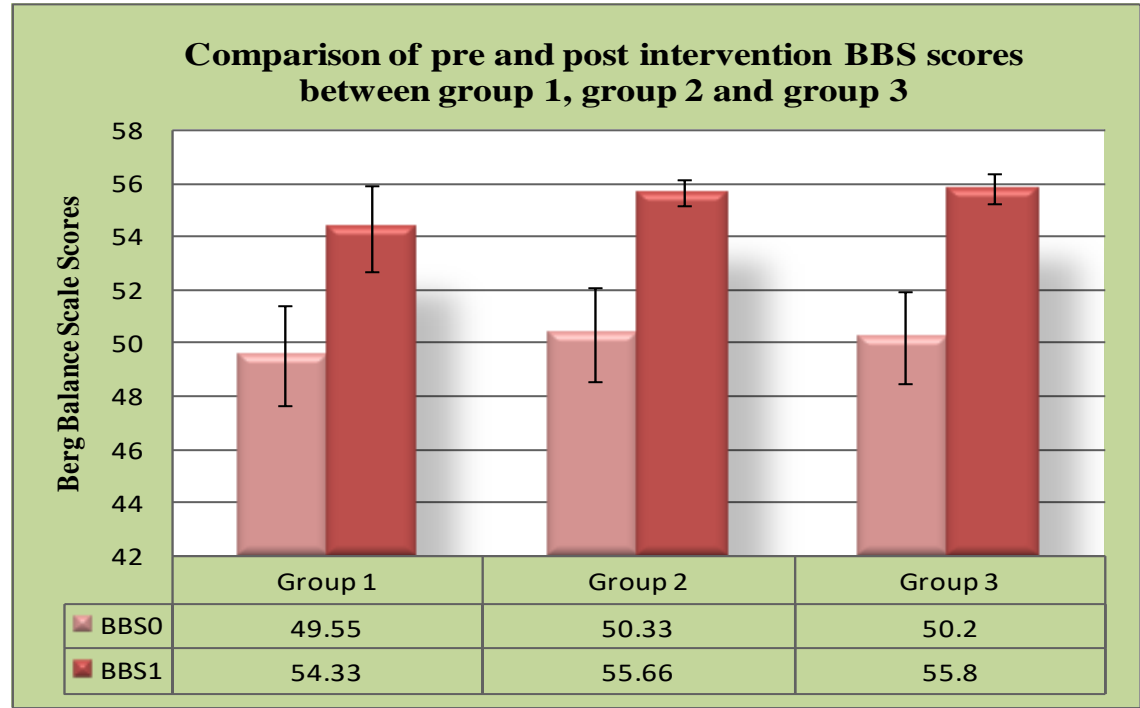

BBS = Berg balance scale

$\mathrm{BBS0}=$ Pre-intervention scores of Berg balance scale

BBS1 $=$ Post-intervention score of Berg balance scale 
Figure 1.3. Comparison of pre and post intervention of time up and go test scores among group 1, 2, 3.

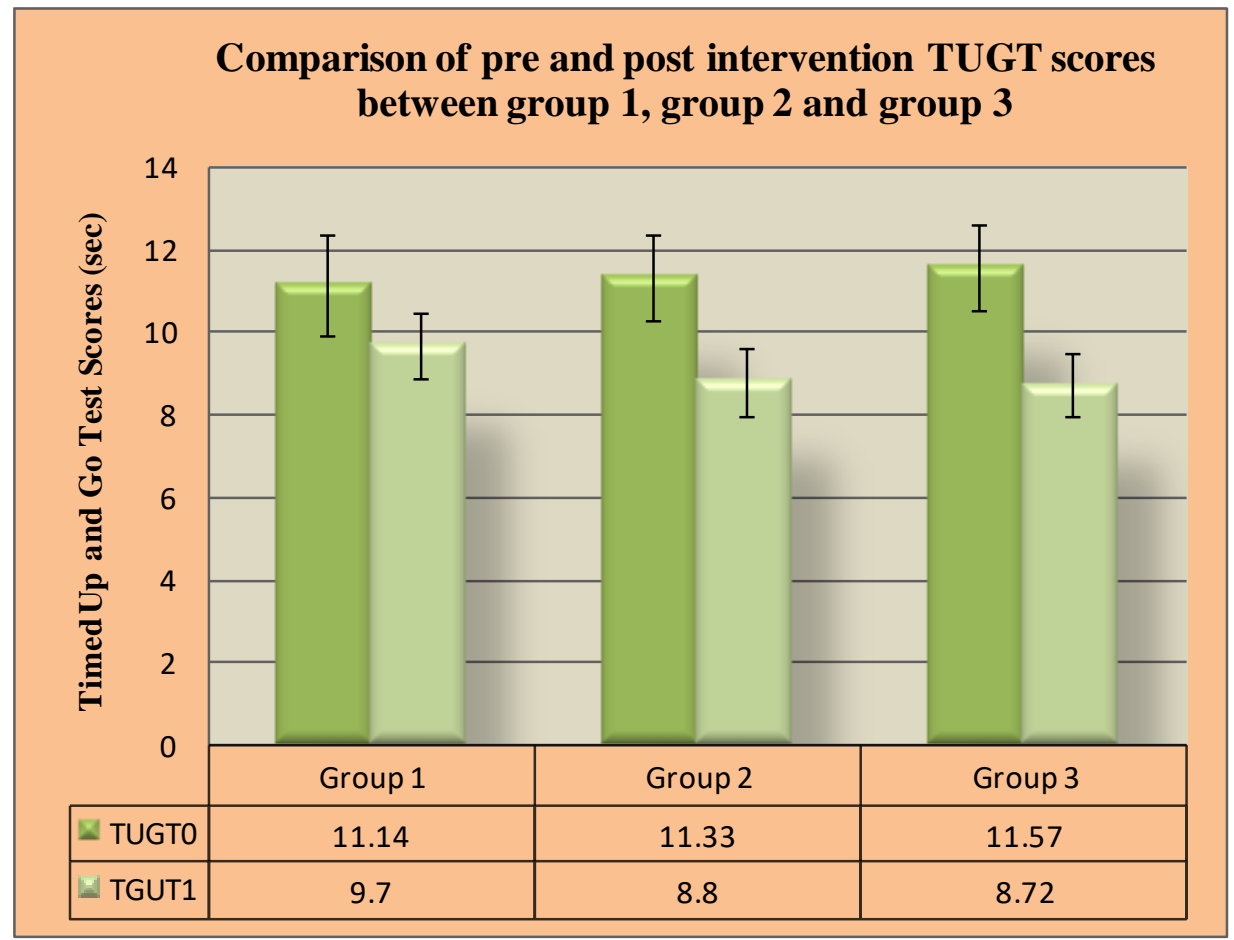

TUGT $=$ Time Up and Go test

TUGT0 $=$ Pre-intervention scores of Time Up and Go Test

TUGT1 $=$ Post-intervention score of Time Up and Go test 